\title{
Sympathetic ophthalmitis: A rare case presentation
}

\author{
P Panjiyar', Parihar NS \\ ${ }^{1}$ Paras Panjiyar, Senior Consultant Ophthalmologist; ${ }^{2}$ Natwar Singh Parihar, Consultant Ophthalmologist; Sagarmatha \\ Choudhary Eye Hospital, Lahan, Nepal
}

\begin{abstract}
Sympathetic Ophthalmitis is a rare, granulomatous uveitis occurring after perforating eye injury or ocular surgical procedure to one eye. The pathophysiologyis not clearly understood. We report a rare case of sympathetic ophthalmitis that presented to us in our hospital.
\end{abstract}

Key words: Granulomatous, Sympathetic Ophthalmitis, Uveitis

\section{INTRODUCTION}

ympathetic Ophthalmitis is a rare, granulomatous Uveitis occurring after perforating eye injury or ocular surgical procedure to one eye ${ }^{1}$. It is also seen after 23-guage vitrectomy, cataract extraction, retinal detachment surgery, penetrating keratoplasty and trabeculectomy ${ }^{2-7}$. The injured eye is called exciting eye and the fellow eye which also develops uveitis is called sympathizing eye. The pathophysiology of this entity is not clearly understood but an autoimmune hypersensitivity reaction against exposed ocular antigens in the injured eye is believed to be responsible for this disease. Incidence of sympathetic ophthalmitis has reduced in the recent years due to meticulous repair of the injured eye utilizing microsurgical techniques and use of the potent steroids. It is more common in children than in adults. It does not occur when actual suppuration develops in the injured eye. Herein, we report a case at Sagarmatha Choudhary Eye hospital, Lahan.

\section{CASE-REPORT}

A seven year old male patient came to hospital with complaint of gradual and painful diminution of vision in left eye since 20 days. He had history of trauma with stone 20 days back in his right eye .Corneal repair was done three days after trauma at a tertiary medical centre in India. The patient did not have any other significant medical and surgical history. On examination, his best

\section{Address for correspondence}

Dr. Paras Panjiyar

Senior Consultant Ophthalmologist

Sagarmatha Choudhary Eye Hospital

Lahan, Nepal

E-mail: paraspanjiyar@hotmail.com corrected visual acuity (BCVA) was Hand movements (HM) in left eye and no perception of light (NPL) in right eye. On biomicroscopic examination, left eye showed multiple mutton fat keratic precipitates (KPs) with +3 cells and flare in the anterior chamber. The pupil was fixed and dilated with posterior synechie formation. The intraocular pressure (IOP) measured $14 \mathrm{~mm} \mathrm{Hg}$. The fundus examination revealed dense vitritis, optic disc edema and retina edema. The patient's right eye was pthisical with horizontal full thickness corneal laceration. The patient wentunder laboratory investigations of complete bloodcount (CBC), erythrocyte sedimentation rate $(E S R)$, rapid plasma reagin (RPR), venereal disease research absorption test (FTA-ABS). Patient also had Xraychest, B-Scan. All laboratory tests including Xray chest were within normal limits. B scan showed mild vitreous opacities with choroidal thickening.

A clinical diagnosis of sympathetic ophthalmitis was entertained and patient was commenced on tablet prednisolone $1 \mathrm{mg} / \mathrm{kg} /$ day individed doses $(1 \mathrm{mg} / \mathrm{kg}$ body weight), prednisolone $1 \%$ drops several times a day and atropine 1\% thrice a day. After three days vison improved to finger counting from one metre.

\section{DISCUSSION}

Various theories have been put forward for pathogenesis. Autoimmune theory, which postulates that the uveal pigment acts as allergen and excites plastic uveitis in the sound eye is widely accepted. The immunologic studies have shown CD4 helper and inducer T cells during the early phase of inflammation compared to infiltration by CD8 suppressor and cytotoxic T cells in the later stage. There are B lymphocytes also found in some patients ${ }^{9}$. It is characteristic of granulomatous 


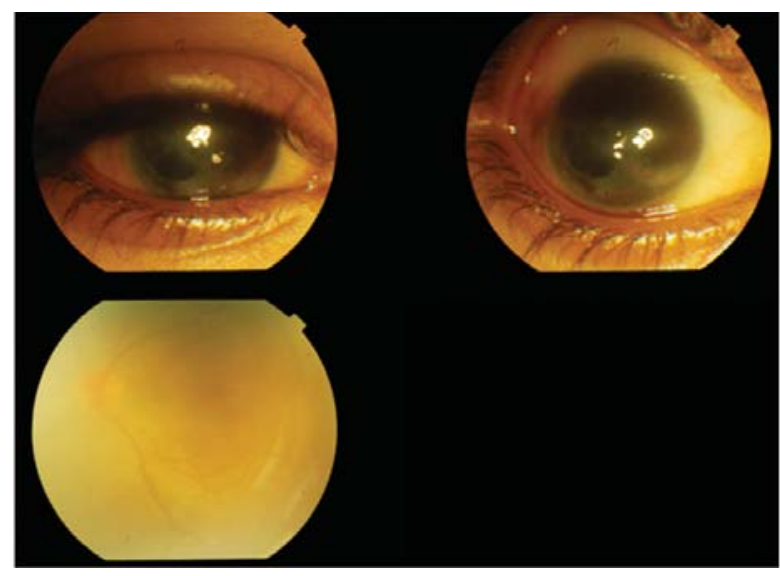

Figure showing the sympathetic ophthalmitis eye

uveitis i.e there is nodular aggregation of lymphocytes, plasma cells, epitheloid cells and giant cells scattered throughout the uveal tract. Dalen-Fuchs' nodules are formed due to proliferation of the pigment epithelium (of the iris, ciliary body and choroid) associated with invasion by the lymphocytes and epitheloid cells. Retina shows perivascular cellular infiltration (sympathetic perivasculitis) ${ }^{11,12}$.

Sympathetic ophthalmitis occurs several days to 50 years after trauma. Most of the cases occur within first year.

\section{REFERENCES}

1. Liddy BSL, Stuart J. Sympathetic Ophthalmitis in Canada. Can J Ophthalmol. 1972; 7: 157-60.

2. Brackup $A B$, Carter KD, Nerad JA et al. Long term follow up of severely injured eyes following globe rupture. Ophthalmic PlastReconstr Surg. 1991; 7: 1994-7.

3. Cha DM, Woo SJ, Ahn J, et al. A case of sympathetic Ophthalmia presenting with extraocular symptoms and conjunctival pigmentation after repeated 23-guages vitrectomy. Ocular Immunallnflamm. 2010; 18: 265-7.

4. Kinyoun JL, Bensinger RE, Chuang EL. Thirty year history of sympathetic ophthalmia. Ophthalmol. 1983; 90: 59-62.

5. Wang WJ. Clinical and histopathalogical report of sympatheticophthalmia after retinal detachment surgery. Br J Ophthalmol.1983; 67: 150-2.

6. Maheshwari S, Rao V. Sympathetic ophthalmia following therapeutic penetrating keratoplasty. Asian J Ophthalmol. 2007; 9: 89-91.
Rarely does it manifest as retinitis and neuroretinitis. Photophobia and loss of accommodation are the early signs. Mutton fat KP's, ciliary congestion, pain, vitritis and disc edema is seen in later stages.

It is important to rule out the other causes of granulomatous uveitis before a diagnosis is confirmed. Although diagnosis of sympathetic ophthalmitis is clinical, histopathology can be confirmatory. Differential diagnosis include VKH, Sarcoidosis, Multifocal Choroiditis, Intraocular lymphoma and bilateral phacoanaphylaxis, tuberculosis and syphilis.

Early excision of the injured eye is the best prophylaxis when there is no chance of saving useful vision. When there is hope of saving useful vision meticulous repair of the wound using microsurgical technique should be done with great care so that uveal tissue is not incarcerated in the wound. Topical as well as systemic steroids and antibiotics and immunomudulation along with topical atropine should be started.

\section{CONCLUSION}

Sympathetic ophtalmitis is a rare disease which is seen after penetrating injury. Careful monitoring is important of injured as well as fellow eye for long time after penetrating ocular trauma.
7. Shammas HF, Zubyk NA, Stanfield TA. Sympathetic Uveitis following glaucoma surgery. Arch Ophthalmol. 1977; 95: 638- 41.

8. Kilmartin DJ, Dick AD, Forrester JV. Sympathetic Ophthalmia risk following vitrectomy. Should we council patients. Br J Ophthalmol. 2000; 84: 448-9.

9. Shah DN, Piacentini MA, Burnier $M N$, et al. Inflammatory cellular kinetics in sympathetic ophthalmia: A study of 29 traumatized (exciting) eyes. Ocullmmunolinflamm 1993; 1: 255- 62.

10. Chan CC, Palestine AG, Nussenblatt RB, et al. Antiretinal auto antibodies in Vogt-Koyanagi-Harada syndrome, Behcet's disease and sympathetic ophthalmia. Ophthalmology. 1985; 92: 1025-8.

11. Rathinam SR, Rao NA. Sympathetic ophthalmia following postoperative bacterial endophthalmitis: A clinicopathologic study. Am J Ophthalmol. 2006; 141: 498-507.

12. Sharp DC, Bell RA, Patterson E, et al. Sypmpathetic Ophthalmia, histopathalogic and angiographic correlation. Arch Ophthalmol. 1984; 102: 202-35. 
13. Jakobiec FA, Marboe CC, Knowles DM, et al. Human sympathetic ophthalmia: an analysis of the inflammatory infiltrate by hybridoma-monoclonal antibodies, immunochemistry, and correlative electron microscopy. Ophthalmology. 1983; 90: 7695.
14. Chan CC, BenEzra D, Rodrigues MM, et al. Imunohistochemisty and electron microscopy of choroidalinfiltrates and Dalen-Fuchs nodules in sympatheticophthalmia. Ophthalmology. 1985; 92: 580-90. 